\title{
EL DERECHO A LA FILOSOFÍA DESDE EL PUNTO DE VISTA COSMOPOLÍTICO
}

\author{
Jacques DERRIDA \\ EHESS, Paris \\ (Traducción de Paco Vidarte)
}

La problemática que constituye la carta de nuestro encuentro internacional ${ }^{1}$ debería imponernos tomar en consideración, al menos a título de ejemplo, dos tipos de relación:

1. La relación interinstitucional entre las universidades o los institutos de investigación por una parte, las instituciones internacionales de la cultura (gubernamentales o no gubernamentales) por otra;

2. La relación interdisciplinar excepcional entre la filosofía, las artes, las ciencias y las "humanidades", nombrando la "filosofía" aquí a la vez una disciplina que forma parte de las "humanidades" y aquella que pretende pensar, elaborar, criticar la axiomática de las «humanidades», especialmente el problema de su humanismo o de su presunto universalismo.

La cuestión acerca de estas dos "relaciones» permanecerá en el trasfondo de las modestas reflexiones preliminares que querría proponerles hoy.

Yo comenzaría por la cuestión "¿dónde?».

No directamente por la cuestión "¿dónde estamos?", "¿en qué punto nos encontramos?", sino "¿dónde tiene lugar la cuestión del derecho a la filosofía?», lo que puede traducirse inmediatamente por "¿dónde debe tener lugar?".

¿Dónde encuentra hoy en día su lugar más apropiado?

1 Palabras recogidas en el transcurso de una introducción a una conferencia organizada por M. SinaCEUR, bajo los auspicios de la Unesco, el 23 de mayo de 1991.

ENDOXA: Series Filosóficas, n. ${ }^{\circ}$ 12, 2000, pp. 381-395. UNED, Madrid 
La forma misma de esta cuestión referida a una pregunta, a saber «¿dónde?, ¿en qué lugar puede tener lugar una cuestión?», supone que entre la cuestión y el lugar, entre la pregunta por la cuestión y la cuestión del lugar, haya una especie de contrato implícito, una supuesta afinidad, como si una cuestión debiera estar siempre previamente autorizada por un lugar, legitimada de antemano por un espacio determinado que le da a la vez derecho y sentido, haciéndola así posible y al mismo tiempo necesaria, a la vez legítima e inevitable.

Según el idioma francés - y ya el uso de este idioma, la autoridad de hecho de este idioma nos lleva a la cuestión de lo cosmopolítico y nos obligaría por sí solo a plantear esta cuestión-, diríamos que hay lugares donde hay lugar a plantear esta cuestión, es decir, que esta cuestión es allí no solamente posible de derecho y está autorizada, sino que es necesaria, incluso prescriptiva. En dichos lugares, tal cuestión, por ejemplo la del derecho a la filosofía desde el punto de vista cosmopolítico, puede y debe tener lugar.

Por ejemplo: la Unesco sería así el lugar privilegiado, tal vez en el fondo, lo digo sin convencionalismos y tampoco en absoluto por cortesía hacia nuestros huéspedes, el único lugar posible para desplegar verdaderamente la cuestión que nos reúne hoy y cuya autoridad lleva en cierto modo, en su forma misma, el sello de esta institución, recibiendo de ella en principio tanto su respuesta como su responsabilidad, como si, por decirlo en una palabra, la Unesco, y en ella muy especialmente su departamento de filosofía, fuera, si se me permite decirlo, la emanación singular de algo así como la filosofia, como «un derecho a la filosofía desde el punto de vista cosmopolíticom, una emanación singular por ser circular, como si una fuente, y la emanación siempre lo es de una fuente, se remontara a la fuente. La Unesco nació quizás de la posición de un derecho a la filosofía desde el punto de vista cosmopolítico. Le correspondería como algo propio responder de este derecho respondiendo a esta cuestión. La Unesco sería a la vez portadora de la respuesta y de la responsabilidad de esta cuestión.

¿Por qué? ¿Por qué la Unesco, en su propio destino, en la misión que se ha asignado, sería la institución que, por antonomasia, hoy, tendría la vocación de plantear esta cuestión, de hacerle justicia a su vez, de elaborarla y de extraer las enseñanzas prácticas de una elaboración semejante?

Mi título hace una alusión transparente al célebre título de un pequeño gran texto de Kant, la Idee zu einer allgemeinen Geschichte in weltbürglicher Absicht (1784), Idea [con vistas a] de una historia universal desde el punto de 
vista cosmopolítico. Como sabemos, este texto breve y difícil pertenece al conjunto de escritos de Kant que podemos decir anuncian, es decir, predicen, prefiguran y prescriben a la vez un cierto número de instituciones internacionales que no han visto la luz sino en este siglo y la mayoría de ellas después de la Segunda Guerra mundial. Estas instituciones, así como la idea del derecho internacional que intentan poner en obra, son ya filosofemas. Son actas/actos y archivos filosóficos, producciones y productos filosóficos, no sólo porque los conceptos que las legitiman tienen una historia filosófica asignable y por tanto una historia filosófica que se halla inscrita en la carta o la constitución de la Unesco; sino porque, al mismo tiempo, y por eso mismo, tales instituciones implican el hecho de compartir una cultura y un lenguaje filosófico, comprometiéndose así a hacer posible, en primer lugar por la educación, el acceso a ese lenguaje y a esa cultura. Todos los Estados que suscriben las cartas de estas instituciones internacionales se comprometen, en principio, filosóficamente, a reconocer $y$ a poner en obra de modo efectivo algo así como la filosofía y una cierta filosofía del derecho, de los derechos del hombre, de la historia universal, etc. La firma de estas cartas es un acto filosófico que compromete filosóficamente ante la filosofía. A partir de ahí, lo digan o no, lo sepan o no, se conduzcan en consecuencia o no, estos Estados y estos pueblos, por su adhesión a estas cartas o por su participación en estas instituciones, contraen un compromiso filosófico, y por tanto, cuando menos, un compromiso de asegurar la cultura o la educación filosófica indispensable para entender y poner en práctica estos compromisos ante las instituciones internacionales que, repito, son filosóficas por esencia (lo que, dicho sea de pasada, algunos pueden interpretar como una apertura infinita, otros como un límite a la universalidad misma, si se considerara, por ejemplo, que un determinado concepto de la filosofía e incluso del cosmopolitismo filosófico, y aun del derecho internacional, es una cosa demasiado europea - pero éste es un problema que reaparecerá sin duda en el transcurso de las discusiones).

¿Qué es lo que está en juego concretamente hoy día en esta situación? ¿Por qué las grandes cuestiones de la enseñanza y de la investigación filosóficas, por qué el imperativo del derecho a la filosofía deben desplegarse más que nunca en su dimensión internacional? ¿Por qué las responsabilidades que hay que tomar ya no son, y mucho menos hoy en día, y aún menos mañana, en el siglo veintiuno, simplemente nacionales? ¿Qué significan aquí "nacional”, "internacional", "cosmopolítico", "universal" para la filosofía y en relación con ella, con la investigación filosófica, con la educación o con la formación filosóficas, 
qué significan incluso para una cuestión o una práctica filosóficas que no se vinculasen esencialmente a la investigación o a la educación?

Un filósofo es siempre alguien para quien la filosofía no está dada, alguien que, por esencia, debe preguntarse sobre la esencia y el destino de la filosofía. Y re-inventarla. Es preciso recordar este hecho incluso si parece trivial o demasiado evidente; porque se trata ahí de una situación y de un deber más singulares de lo que parecen; y ello puede conducir a consecuencias prácticas temibles. La existencia de lugares tales como la Unesco, es decir, de instituciones internacionales que no sólo implican una filosofía, e incluso la filosofía, en el discurso y yo diría aun en la lengua de su carta, sino que han juzgado necesario dotarse de un departamento especializado de filosofía (lo que no es obvio y recuerda todo el debate abierto desde El conflicto de las facultades de Kant: ¿por qué una institución esencialmente filosófica tendría necesidad de un departamento de filosofía? Schelling pensaba, en contra de Kant, que no siendo la Universidad más que una gran institución filosófica, filosófica de parte a parte, debiendo estar allí la filosofía por todas partes, no había lugar para encerrarla en un departamento), la existencia, pues, de un lugar propiamente filosófico como la Unesco, el hecho de que el modo de ser de la Unesco es un modo de ser a priori filosófico constituye, me parece, una especie de axiomática, un sistema de valores, de normas, de principios reguladores en virtud de los cuales, ciertamente, estamos aquí, pero que prescriben asimismo a todo filósofo preguntarse concretamente acerca de una situación semejante y no considerarla como algo dado, evidente y sin consecuencia grave alguna.

Antes de sacar algunas conclusiones preliminares y menos abstractas de estos primeros axiomas, permítanme recordarles que el texto de Kant, si anuncia y prescribe un "estado cosmopolítico universal» (estado, Zustand, en el sentido del estado de las cosas, de la situación, de la constitución real, no del Estado con E mayúscula), si Kant define cuando menos su esperanza (Hoffnung), la esperanza de que, tras muchas revoluciones y transformaciones, "finalmente (endlich)" este cosmopolitismo llegará a ser un hecho, si Kant funda esta esperanza (que sigue siendo una esperanza) en el designio "supremo de la naturaleza" (was die Natur zur höchsten Absicht hat), esa esperanza es cualquier cosa menos la expresión de un optimismo confiado y menos aún de un universalismo abstracto. $\mathrm{Al}$ subrayar brevemente algunos limites que le dan su forma misma — su forma, a la vez, la más positiva, la más moderna, la más rica en enseñanza pero también la más problemática- al discurso kantiano, al insistir más bien en las dificultades, querría introducir a las exposiciones y a la 
discusión que vendrán a continuación, introducirlos y no, por supuesto, anticiparlos, precederlos, menos aún preverlos o programarlos.

¿Cuáles son estas dificultades? ¿Qué prefiguran de las tareas y de los problemas de nuestro tiempo? Pero también, ¿qué no prefiguran?, ¿y qué es lo que en nuestro tiempo podría, y hasta debería desbordar un discurso como el de Kant?

La Idea (en el sentido kantiano) que nos reúne aquí en la conciencia de que la definición de una tarea filosófica y de un derecho a la filosofía debe ser planteada en su dimensión cosmopolítica, por tanto inter-nacional o inter-estatal (y ya es una grave cuestión saber si lo cosmopolítico traza aquí un nexo de unión entre las ciudades, las poleis del mundo como naciones, como pueblos o como Estados) supone, el propio Kant lo dice, una aproximación filosófica a la historia universal inseparable de una especie de plan de la naturaleza con vistas a una unificación política total, perfecta de la especie humana (die vollkommene bürgerliche Vereinigung in der Menschengattung). Quien dudara de una unificación así y sobre todo de un plan de la naturaleza no tendría razón alguna para suscribir ni siquiera la puesta en común de una problemática filosófica, de una problemática supuestamente universal o universalizable de la filosofía. Para quien dudara de este plan de la naturaleza, todo el proyecto de escribir una historia universal - por tanto, filosófica- y, por consiguiente, también el proyecto de crear instituciones regidas por un derecho internacional -y, por tanto, filosófico- no sería más que una novela.

"Novela" es la palabra que emplea Kant. Es tan consciente del riesgo que, en varias ocasiones, juzga necesario dar explicaciones sobre esta hipótesis o esta acusación y para ello reafirmar que esta idea filosófica, por extravagante que parezca, no es ni una ficción ni una historia de novela. La filosofía, en el cuerpo en formación de su institución, sobre todo no es literatura, insiste, ni más generalmente una ficción, en todo caso una ficción de lo imaginario. Pero el peligro de la literatura, del convertirse-en-literatura de la filosofia, es tan apremiante, y tan presente para Kant, que éste la nombra y la recusa en varias ocasiones. Pero, para hacer esto, le es preciso a la vez invocar el hilo conductor de un designio de la naturaleza (el hilo conductor, es decir, un instrumento cómodo de la representación (Darstellung), lo que no es el modo más seguro de escapar de la novela) y, por otra parte, tomar como hilo conductor más seguro, para seguir este mismo hilo conductor, la historia de las naciones europeas y, ante todo, su comienzo griego, luego romano, en oposición a las naciones lla- 
madas bárbaras. Lo que hace que este texto de espíritu cosmopolítico, según una ley que se podría verificar mucho más allá de Kant, sea el texto más fuertemente eurocentrado que hay, no sólo en su axiomática filosófica, ciertamente, sino en su referencia retrospectiva a la historia greco-romana y también en su referencia prospectiva a la hegemonía futura de Europa, la cual, dice Kant, «verdaderamente dará un día las leyes a todas las demás [naciones]".

Como esta cuestión difícil y apremiante del modelo europeo, incluso continental, de la filosofía no dejará, supongo (y, en verdad, lo espero), de resurgir en el debate que nos espera, me gustaría evocar algunas líneas de Kant. Éstas ponen de manifiesto que el único medio de oponer la razón filosófica a la novela o a la ficción extravagante es, al menos a ojos de Kant, fiarse de la historia europea de la razón y, en primer lugar, de la historia greco-romana de la historia. En la Séptima Proposición, Kant recuerda que la naturaleza habrá utilizado natural y paradójicamente la insociabilidad natural de los hombres (y Kant es pesimista al creer en esta insociabilidad natural del hombre y en el estado de guerra natural $u$ originaria entre los hombres) para obligarlos a contraer vínculbs artificiales $e$ institucionales $y$ a entrar en una Sociedad de Naciones:

«La naturaleza ha utilizado, pues, una vez más, la insociabilidad (Ungeselligkeit, Unvertragsamkeit) de los hombres e incluso la insociabilidad entre grandes sociedades y cuerpos políticos, a los que se presta esta especie de criaturas, como un medio para forjar en el seno de su inevitable antagonismo un estado de calma y de seguridad. Así, por medio de las guerras, de los preparativos excesivos e incesantes en vista de las guerras y de la miseria que ello ocasiona en el interior de cada Estado, incluso en tiempos de paz, la naturaleza, mediante tentativas primero imperfectas, luego, finalmente, tras muchas ruinas, no pocos naufragios, incluso tras un agotamiento interior radical de sus fuerzas, empuja a los Estados a hacer lo que la razón habría podido igualmente enseñarles sin que ello les costara tantas y tan tristes experiencias, es decir, los empuja a salir del estado anárquico de salvajismo para entrar en una Sociedad de Naciones. Allí, cada uno, incluido el Estado más pequeño, podría conseguir la garantía de su seguridad y sus derechos no por sù propia fuerza o por la propia apreciación de su derecho, sino únicamente por esta gran Sociedad de Naciones [de pueblos: Völkerbunde] (foedus amphictyonum), es decir, por una fuerza unida y por una decisión tomada en virtud de las leyes fundadas en el acuerdo de las voluntades. Por muy novelesca [más precisamente, por muy exaltada, entu- 
siasta, schwärmerisch] que pueda parecer esta idea y por mucho que haya sido ridiculizada por el Abate de Saint-Pierre o Rousseau (quizás porque creían muy próxima su realización), tal es no obstante la salida inevitable de la miseria en la que se sumergen unos a otros los hombres y que debe forzar a los Estados a adoptar la resolución, etc ${ }^{2}$ ".

La lógica de esta teleología es que debemos estarle agradecidos a la naturaleza - Kant lo dice literalmente- por habernos creado naturalmente, originariamente, $\tan$ insociables y poco filósofos que necesitamos el empuje de la cultura, del arte y del artificio (Kunst), así como de la razón, para hacer florecer las semillas de la naturaleza.

Esta astucia de la naturaleza se parece, sin serlo, a una historia novelesca y no es, en verdad, sino la historicidad misma de la historia. La naturaleza hace uso del desvío de la violencia y de la insociabilidad primitivas, así pues naturales, para servir a la razón y, por tanto, para poner en marcha la filosofía a través de la sociedad de naciones. Ahora bien - y es ahí donde encontraríamos una provocación paradojica para los debates de hoy en día-, en esta astucia teleológica de la naturaleza, la Europa greco-romana, la filosofia y la historia occidentales, me atrevería incluso a decir continentales, juegan un papel motor, capital, ejemplar, como si la naturaleza, en su estrategia racional, hubiera encargado a Europa esta misión especial: no sólo la de fundar la historia como tal, y ante todo como ciencia, no sólo la de fundar la filosofía como tal, $\mathrm{y}$ ante todo como ciencia, sino también la de fundar una historia filosófica racional (no novelesca) y de "dar un día leyes" a todos los demás continentes.

Kant reconoce una segunda vez, en la Novena Proposición, que el intento filosófico de tratar la historia universal en función de un designio oculto de la naturaleza y con vistas a una unificación política total de la humanidad se parece a una novela (y allí nombra a la novela por su nombre, Roman). Pero, para contradecir esta hipótesis novelesca y pensar la historia humana, más allá de la novela, como un sistema y no como un agregado sin plan y sin programa, sin providencia, se refiere a lo que llama el hilo conductor (Leitfaden) de la historia griega (griechische Geschichte), "la única, dice, que nos transmite

2 Kant, Philosophie de l'histoire, Aubier, traducción, Stéphane Piobetta (a veces, ligeramente modificada), págs. 69-70 (Traducción castellana de E. Imaz. México, Fondo de Cultura Económica, 1989, págs. 52-53). 
todas las otras historias que le son anteriores o contemporáneas o que al menos nos aporta documentos al respecto".

Dicho de otro modo, la historicidad y la historiograficidad griega serían el signo, el indicio y, por tanto, el hilo conductor que permitiría pensar que una historia es posible, que reuniría todo cuanto atañe a la universalidad del género humano. Podemos seguir la influencia de esta historia griega (a la vez en el sentido de Geschichte y de Historie, de historia en el sentido del acontecimiento y del relato, de la relación documentada, de la ciencia histórica), dice Kant, en la formación y el declive del cuerpo político del pueblo romano en tanto que ha "absorbido" la pólis griega, luego ha esbozado la cosmópolis influyendo o colonizando a los bárbaros que, a su vez, destruyeron Roma.

Y Kant añade:

"Adjuntemos a esto al mismo tiempo, episódicamente (episodisch), la historia política de los otros pueblos tal y como su conocimiento ha llegado poco a poco a nosotros precisamente por la mediación de estas naciones esclarecidas. Se verá entonces aparecer un progreso regular del perfeccionamiento de la constitución política en nuestro continente (in unserem Weltheile) (que verosímilmente dará un día leyes a todos los demás, der warscheinlicher Weise allen anderen dereinst Gesetze geben wird)".

El eje teleológico de este discurso ha llegado a ser la tradición de la modernidad europea. Lo encontramos intacto, incapaz de cambios a través de las variaciones tan graves como las que pueden distinguir a Hegel, Husserl, Heidegger, Valéry. Lo encontramos asimismo en estado práctico y a veces a través de la denegación, en numerosos discursos político-institucionales, europeos o mundiales. Ahora bien, este discurso eurocéntrico nos empuja a preguntarnos - y lo diré de modo esquemático para no conservar mucho tiempo la palabra - si hoy en día nuestra reflexión sobre la extensión sin límite y la reafirmación de un derecho a la filosofía no debe a la vez tener en cuenta y de-limitar la asignación de la filosofía a su origen o a su memoria greco-europea. No habría que contentarse con reafirmar una cierta historia, una cierta memoria de los orígenes o de la historia occidental (mediterránea o centroeuropea, greco-romana-árabe o germánica) de la filosofia, ni contentarse tampoco con oponerse u oponer la denegación a esta memoria y a estas lenguas, sino intentar desplazar el esquema fundamental de esta problemática yendo más allá de la vieja, fatigante, extenuada, extenuante oposición entre el eurocentrismo y el anti-eurocentrismo. 
Una de las condiciones para llegar a ello - y no llegaremos a esto de golpe, sino que será el efecto de una larga y lenta labor histórica en curso-, es la toma de conciencia activa del hecho de que la filosofía ni está determinada por un programa, un lenguaje o una lengua originarias cuya memoria bastaría reencontrar para revelar a partir de ahí su destino, ni está asignada a su origen o por su origen, como tampoco es ella simplemente, espontáneamente, abstractamente cosmopolítica o universal. Aquello de lo que tenemos experiencia, cada vez más, es de los modos de apropiación y de transformación de lo filosófico, en lenguas y culturas no-europeas, que no se reducen ni al modo clásico de la apropiación -que consiste en hacer suyo lo que es del otro (aquí a interiorizar la memoria occidental de la filosofía y asimilarla en su propia lengua) - , ni a la invención de nuevos modos de pensamiento que, extraños a cualquier apropiación, no tendrían ya ninguna relación con lo que creemos reconocer bajo el nombre de filosofía.

Lo que tiene lugar hoy en día, y creo que desde hace mucho, son formaciones filosóficas que no se dejan encerrar en esta dialéctica, en el fondo cultural, colonial o neocolonial, de la apropiación y de la alienación. Hay otras vías para la filosofía distintas de la apropiación como expropiación (perder su memoria al asimilar la memoria de la otra, oponiéndose una a la otra, como si una ex-apropiación no fuera posible, la única oportunidad posible).

No sólo hay otras vías para la filosofía, sino que la filosofía, si la hay, es la otra vía.

Y siempre ha sido la otra vía: la filosofia nunca ha sido el despliegue responsable de una única asignación originaria vinculada a la lengua única o al lugar de un solo pueblo. La filosofía no tiene una sola memoria. Bajo su nombre griego y en su memoria europea siempre ha sido bastarda, híbrida, injertada, multilineal, políglota y nos es preciso ajustar nuestra práctica de la historia de la filosofía, de la historia y de la filosofía, a esta realidad que fue también una oportunidad y que permanece más que nunca como una oportunidad. Lo que digo aquí de la filosofía puede decirse también, y por las mismas razones, del derecho y de la democracia.

En filosofía como en otras partes, el europeocentrismo y el anti-europeocentrismo son síntomas de la cultura misionera y colonial. Un concepto del cosmopolitismo que estuviera aún determinado por esta oposición, no sólo limitaría concretamente el desarrollo del derecho a la filosofía, sino que ni siquiera daría cuenta de lo que ocurre en filosofía. Para reflexionar en la direc- 
ción de lo que ocurre y aún podría ocurrir bajo el nombre de filosofia (y este nombre es la vez muy grave y sin importancia, según lo que se haga con él), nos es preciso reflexionar sobre lo que pueden ser las condiciones concretas del respeto y de la extensión del derecho a la filosofia.

Yuxtapondré aquí muy rápidamente los títulos de los problemas que, en verdad, están sistemática o estructuralmente coordinados.

1. Primer titulo. Quienquiera que piense que hay que hacer respetar, conceder, extender el derecho a la filosofía de un punto de vista cosmopolítico debería tener en cuenta lo que es, pero también lo que siempre ha sido, la competencia entre varios modelos, estilos, tradiciones filosóficas vinculadas a historias nacionales o lingüísticas, incluso si nunca se reducen a efectos de nación o de lengua. Por tomar el ejemplo más canónico, que está lejos de ser el único y que comporta a su vez numerosas sub-variantes, la oposición entre la tradición de la llamada filosofía continental y la llamada filosofía analítica o anglo-sajona no se reduce ni a límites nacionales ni a datos lingüísticos. Esto no constituye sólo un inmenso problema y un enigma para los filósofos europeos o anglo-americanos que se han formado en este contexto. Una cierta historia, especialmente, pero no solamente, una historia colonial, ha constituido a estos dos modelos en referencias hegemónicas en el mundo entero. El derecho a la filosofía pasa no sólo por una apropiación de estos dos modelos concurrentes - $\mathrm{y}$, en el límite, de cualquier modelo- por todos y por todas (y cuando digo todas, no es para ser formalmente prudente en lo tocante a las categorías gramaticales, vuelvo a ello en un instante); el derecho de todos y de todas a la filosofía pasa asimismo por la reflexión, el desplazamiento y la desconstitución de estas hegemonías, el acceso a lugares y a acontecimientos filosóficos que no se agotan ni en estas dos tradiciones dominantes ni en estas lenguas. Los asuntos que están aquí en juego son ya intra-europeos ${ }^{3}$.

2. Segundo título. El respeto y la extensión del derecho de todos y de todas a la filosofía supone también, lo digo de nuevo demasiado deprisa, la apropiación pero asimismo el desbordamiento de las lenguas que se dicen,

3 Estos temas son desarrollados en los textos publicados por el Greph, el College International de Philosophie (especialmente en su acta de fundación) y en algunos de mis ensayos, entre los cuales, por ejemplo, Du droit à la philosophie, Galilé, 1990 y L'Autre Cap, La démocratie ajournée, Minuit, 1991 (Traducción castellana de P. Peńalyer. Barcelona, Serbal, 1992). 
según el esquema que ponía en cuestión hace poco, fundadoras u originarias de la filosofía, las lenguas griega, latina, germánica o árabe. La filosofía debe practicarse, según caminos no simplemente anamnésicos, en lenguas que no tienen una relación de filiación con estas raíces. Si la extensión, con la mayor frecuencia hegemónica, de esta o aquella lengua y de modo casi todopoderoso, me refiero al inglés, puede servir de vehículo para la penetración universal de lo filosófico y de la comunicación filosófica, la filosofía exige al mismo tiempo, y por esto mismo, que nos liberemos de los fenómenos de dogmatismo y de autoridad que la lengua puede producir. No se trata de sustraer la filosofía a la lengua y a lo que para siempre la vincula a lo idiomático; no se trata de promover un pensamiento filosófico abstractamente universal y sin inherencia al cuerpo del idioma, sino, por el contrario, de ponerla en obra de una forma original cada vez en una multiplicidad no finita de idiomas que produzcan acontecimientos filosóficos que no sean ni particularistas e intraducibles ni abstractamente transparentes y unívocos en el elemento de una universalidad abstracta. Con una sola lengua siempre es una filosofía, una axiomática del discurso y de la comunicación filosóficas, las que se imponen sin discusión posible. Diría algo semejante, en todo caso dependiente de la misma lógica, referido a la ciencia y a la técnica. Es evidente que el desarrollo de las ciencias y de las técnicas (ya se trate de física teórica, de astrofísica o de genética, de informática o de medicina, ya estén al servicio de la economía o incluso de la estrategia militar) es, para bien o para mal, el abrirse paso de una comunicación cosmopolítica y, a este título, abre camino, por el rodeo de la investigación científica pero también de la epistemología o de la historia de las ciencias, a lo que en la filosofía, y desde siempre, habrá sido solidario, según modos diferentes, del movimento de la ciencia. La hipótesis o el deseo que estaría tentado de someter a discusión es que, teniendo en cuenta o haciéndose cargo de este progreso de las ciencias, en el espíritu de una nueva era de las Luces para este nuevo milenio ( $\mathrm{y}$ a este respecto sigo siendo kantiano), una política del derecho a la filosofía para todos y para todas no sea solamente una política de la ciencia y de la técnica, sino una política del pensamiento que no ceda ni al positivismo, ni al cientificismo, ni al epistemologismo y encuentre, de acuerdo con lo que últimamente está en juego, en su relación con la ciencia, así como con las religiones, pero también con el derecho y con la ética, una experiencia que sea a la vez de provocación o de respeto recíproco, pero asimismo de autonomía irreductible. Los problemas son a este respecto siempre tradicionales y siempre nuevos, ya se trate de ecología, de bioética, de inseminación 
artificial, de transplantes de órganos, de derecho internacional, etc. Todos atañen por tanto al concepto de lo propio, de la propiedad, de la relación consigo y con el otro en los valores de sujeto y de objeto, de subjetividad, de identidad, de persona, es decir, a todos los conceptos fundamentales de las cartas que rigen las relaciones y las instituciones internacionales, como el derecho internacional que se supone las debe regular en principio.

Habida cuenta de aquello que vincula a la ciencia con la técnica, con la economía, con los intereses político-económicos o político-militares, la autonomía de la filosofía respecto a la ciencia es tan esencial para la práctica de un derecho a la filosofía como la autonomía respecto de las religiones es esencial para quien quiera que el acceso a la filosofía no le sea prohibido a nadie. Hago aquí alusión a lo que, en cada área cultural, lingüística, nacional, religiosa, puede limitar el derecho a la filosofía por razones sociales, políticas o religiosas, en razón de la pertenencia a una clase, a una edad, a un sexo $\longrightarrow$ o todo ello a la vez.

Aquí, me arriesgaré a afirmar que, más allá de lo que vincularía a la filosofía con su memoria greco-europea o con las lenguas indoeuropeas, más allá incluso de lo que la vincularía con un modelo occidental ya constituido de lo que se llama en griego la democracia, me parece imposible disociar el motivo del derecho a la filosofía "desde el punto de vista cosmopolítico» del motivo de una democracia por venir. Sin vincular el concepto de democracia a sus datos pasados y mucho menos a los hechos que se han clasificado bajo este nombre, y que guardan todos en sí la huella de las hegemonías que he evocado más o menos directamente, no creo que el derecho a la filosofía (tal y como una institución internacional como ésta debe hacerlo respetar y extender su efectividad) sea disociable de un movimiento de democratización efectivo.

Ustedes imaginan bien que cuanto digo es todo menos un deseo abstracto y una concesión convencional a consenso democrático alguno. Los asuntos en juego nunca han sido tan graves en el mundo de hoy en día y son asuntos nuevos, que apelan a una nueva reflexión filosófica sobre lo que la democracia, e insisto, la democracia por venir, puede querer decir y ser. No queriendo extenderme demasiado en esta introducción, me reservo la posibilidad de decir algo más sobre esta cuestión en el debate.

3. Tercer título. Aunque la filosofía no se reduzca a sus momentos institucionales o pedagógicos, es evidente que todas la diferencias de tradición, de estilo, de lengua, de nacionalidad filosófica están traducidos o encarnados en 
los modelos institucionales o pedagógicos, a veces incluso están producidos por estas estructuras (la escuela, el colegio, el instituto, la universidad, las instituciones de investigación). Ese es el lugar de las discusiones, de las competencias, de guerra o de comunicación de los que hablaremos enseguida, pero me gustaría, para concluir sobre este punto, volverme por última vez hacia Kant para situar aquello que puede constituir hoy el límite o la crisis más común a todas las sociedades, occidentales o no, que desearían poner en obra un derecho a la filosofía. Lo que ocurre es que, más allá de los motivos políticos o religiosos, más allá de los motivos de apariencia filosófica que pueden empujar a limitar el derecho a la filosofía, incluso a prohibirla (a tal clase social, a las mujeres, a los adolescentes antes de una cierta edad, etc., a los especialistas de esta o aquella disciplina o a los miembros de este o aquel grupo), más allá incluso de todos los motivos de discriminación a este respecto, la filosofía sufre en todas partes, en Europa y en otros lugares, en su enseñanza y en su investigación, una limitación que, aun no tomando siempre la forma explícita de la prohibición o de la censura, no por ello deja de ser una limitación, aunque sólo sea por el recorte de los medios de los que se dispone para financiar la enseñanza y la investigación filosóficas. Dicho recorte está motivado, no digo justificado, tanto en las sociedades de tipo capitalista liberal, socialistas o socialdemócratas, por no hablar de regímenes autoritarios o totalitarios, por equilibrios presupuestarios que le conceden la prioridad a las investigaciones y a la formación en la investigación susodicha, con frecuencia por un motivo justo, útil, rentable, urgente, a la ciencia, digámoslo así, aplicada, a los imperativos tecno-económicos, incluso a lo científico-militar. No se trata en absoluto para mí de poner en cuestión indistintamente todos estos imperativos. Pero cuanto más se imponen dichos imperativos y a veces por las mejores razones, en ocasiones con vistas a desarrollos sin los cuales el propio despliegue de la filosofía no tendría ninguna oportunidad en el mundo, tanto más urgentes, irreductibles se hacen el derecho a la filosofía y la llamada a la filosofia, precisamente para pensar y discernir, evaluar, criticar las filosofías, porque también son filosofías las que, en nombre de un positivismo tecno-económico militar, e incluso de un "pragmatismo" o de un "realismo", tienden a reducir, según diversas modalidades, el campo y las oportunidades de una filosofía abierta y sin límite, en su enseñanza y en su investigación, así como en la efectividad de sus intercambios internacionales.

He aquí el porqué, y de momento ya he terminado con ello, de la cierta reserva que he creído necesario señalar respecto al concepto kantiano (a la vez 
demasiado naturalista y demasiado teleológico-europeo) de la cosmópolis, citaré aún a Kant para concluir. Citaré lo que él llama ejemplarmente un ejemplo. Su corto tratado sobre la Idea de una historia universal desde el punto de vista cosmopolítico es evidentemente también, como no podía ser de otro modo, un tratado de la educación. Y en su Octava Proposición, después de haber anunciado y saludado "la era de las Luces" y la "libertad universal de religión", Kant escribe lo siguiente, que sigue siendo algo que hay que meditar hoy día, casi sin necesidad de trasposición.

Si tuviera que darle un título a este pasaje, éste sería tal vez: "De la filosofía -la deuda y el deber".

"Estas Luces, y con ellas también un cierto afecto -del que el hombre ilustrado inevitablemente da muestras- por el bien del que tiene perfecta inteligencia, deben poco a poco acceder hasta los tronos y tener a su vez una influencia sobre los principios de gobierno. Tomemos un ejemplo: si nuestros gobiernos actuales no encuentran más dinero para subvencionar los establecimientos de educación pública, y de una manera general para todo aquello que representa en el mundo los verdaderos valores (das Weltbeste) porque todo se ha gastado ya de antemano para la guerra por venir, su verdadero interés reside no obstante en no obstaculizar al menos los esfuerzos, ciertamente muy débiles y lentos, que sus pueblos logran a título privado en este ámbito. Y finalmente la guerra no se reduce a ser una empresa de muy sutiles engranajes, muy incierta en su desenlace para ambos campos; sino también [muy de sopesar] por las lamentables consecuencias de las que se resiente el Estado aplastado por el peso de una deuda siempre creciente (esto es una invención moderna, Schuldenlast einer neuen Erfindung), y cuya amortización llega a ser imprevisible [amortización es Tilgung, la anulación, el borramiento de la deuda, la destrucción que Hegel distingue de la Aufhebung, de la superación, que borra conservando], acabando por convertirse en un asunto espinoso; al mismo tiempo, la influencia que la sola quiebra de un Estado ejerce sobre todos los demás acaba por hacerse tan sensible (tan ligado está cada uno de ellos a los otros en nuestro continente por sus industrias) que éstos se ven obligados por temor al peligro que los amenaza, y fuera de cualquier consideración legislativa, a ofrecerse como árbitros, y así, con mucha antelación, a hacer los preparativos para el advenimiento de un gran organismo político futuro del que el mundo pasado no podría ofrecer ningún ejemplo. [Esta incidencia no reaviva sólo la gran cuestión de la deuda en sus efectos geo-políticos determinantes hoy para el porvenir del mundo, sino que abre el camino para una lectura menos, digá- 
moslo así, tradicionalista y quizás menos teleologista de Kant que la que acabo de esbozar hace un momento]. Aunque este organismo político no sea aún por el momento más que un boceto muy tosco, un sentimiento se abre paso entre todos sus miembros; la conservación de la colectividad (Erhaltung des Ganzen) les importa. Lo que da la esperanza de que tras muchas revoluciones y muchos cambios, finalmente, lo que es el designio supremo de la naturaleza, un Estado cosmopolitico universal, llegará a establecerse un dia. núcleo donde se desarrollarán todas las disposiciones originarias del género humano».

El derecho a la filosofia pasa tal vez desde entonces por una distinción entre varios regímenes de la deuda, entre una deuda finita y una deuda infinita, una deuda interior y una deuda "exterior", entre la deuda y el deber, un cierto borramiento y una cierta reafirmación de la deuda - y, a veces, un cierto borramiento en nombre de la reafirmación. 